\title{
Balloon Mitral Valvuloplasty in Rheumatic Double Orifice Mitral Valve
}

\author{
Mayur Jain, Neerav Panchani, No Bansal, Bhanu Duggal \\ Department of Cardiology, Grant Medical College and Sir J.J. Group of Hospitals, Mumbai, India \\ Email: dr.mayur2409@gmail.com, bahnuduggal2@gmail.com
}

Received 20 February 2015; accepted 23 October 2015; published 27 October 2015

Copyright (C) 2015 by authors and Scientific Research Publishing Inc.

This work is licensed under the Creative Commons Attribution International License (CC BY). http://creativecommons.org/licenses/by/4.0/

(c) () Open Access

\begin{abstract}
We are reporting four cases of acquired double orifice mitral valve (DOMV) of rheumatic etiology (rare) presenting as significant mitral stenosis (MS) treated successfully by percutaneous intervention. All four patients are young ( 3 males, 1 female) who presented with dyspnea of Newyork heart association (NYHA) class II with mean duration of 1.3 years. Typical clinical findings of MS were present in all. Echocardiography confirmed the diagnosis of moderate to severe MS of rheumatic etiology with double orifice of mitral valve of Trowitzsch incomplete bridge variety [1], giving appearance of two equal (like a pair of spectacles in one patient) or unequal size orifices (in three patients) in parasternal short axis view. Color Doppler examination revealed separate jets originating from each orifice, determined severity of the lesion and evaluated the eligibility for balloon mitral valvuloplasty (BMV). BMV was carried out under transeosophagial echo (TEE) guidance (for perfect septal puncture and crossing the separate orifices) using Inoue balloon of appropriate size (in accordance with patient's height) with intention to break central fibrous strand converting into a single orifice. All four patients underwent successful BMV (clinical \& ECHO criteria) after dilating the separate orifices (except case 4) but the fibrous strand could not be broken. Hence, this study shows that good results can be obtained in acquired double orifice mitral valve with significant MS with BMV even without breaking the fibrous strand. Considering rarity of isolated DOMV cases and rheumatic etiology being very rare, this report of four rheumatic acquired DOMV cases with successful BMV done with good result is significant.
\end{abstract}

\section{Keywords}

Rheumatic, Valvuloplasty, Mitral, Stenosis, DOMV

\section{Introduction}

Double orifice mitral valve (DOMV) is an uncommon anomaly that was first described by Greenfield in 1876

How to cite this paper: Jain, M., Panchani, N., Bansal, N. and Duggal, B. (2015) Balloon Mitral Valvuloplasty in Rheumatic Double Orifice Mitral Valve. World Journal of Cardiovascular Diseases, 5, 296-302.

http://dx.doi.org/10.4236/wjcd.2015.510033 
[2]. Since that time, about 220 cases including congenital and acquired have been reported [2]. Most common cause of DOMV is congenital wherein there is abnormal subvalvular apparatus which leads to separate tendinous insertions and formation of two orifices in mitral valve [1]. It is usually associated with other congenital anomalies like atrioventricular septal defect (AVCD), outflow tract obstructions etc. [1]. The main modality of treatment is surgical [3]-[8]. We are here describing four cases of DOMV of rheumatic origin which is among the rarest cause of DOMV. Though the incidence of rheumatic heart disease in India is higher compared to the west, getting mitral valve with two orifices is very rare. Hence, this report of 4 cases of DOMV of rheumatic origin managed without surgery is significant. Percutaneous balloon mitral valvuloplasty is a time tested treatment for rheumatic mitral stenosis since 1984 [9], but for valves with single orifice. The long term outcome for BMV in DOMV is still not known.

\section{Materials \& Methods}

Patients attending the cardiology outpatient department and inpatients admitted to cardiology wards who had complains of class II or more dyspnea and clinical findings suggestive of MS i.e. tapping apex, loud S1, opening snap (OS), mid diastolic murmur at apex etc were screened with detailed clinical history and examination. For detailed assessment of mitral and other valves and to determine severity of MS and line of management, two dimensional echocardiography and color Doppler examination (VIVID 7, GE) were carried out using $3 \mathrm{MHz}$ transducer appropriately focused according to patient's size (Table 1). Parasternal short axis view (PSAX) revealed mitral valve to have double orifice which showed 2 separate jets on color Doppler examination (Figure 1 and Figure 2).

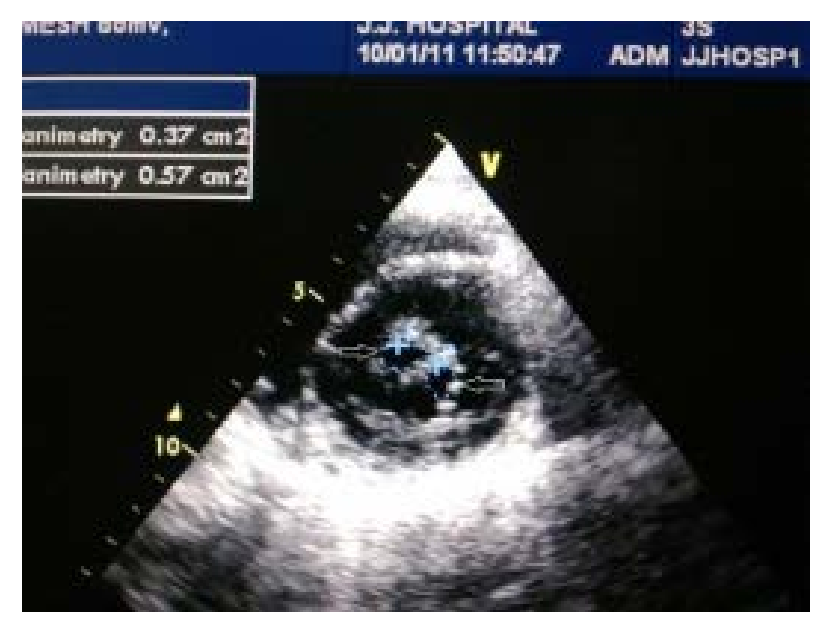

Figure 1. Double orifice mitral valve in PSAX.

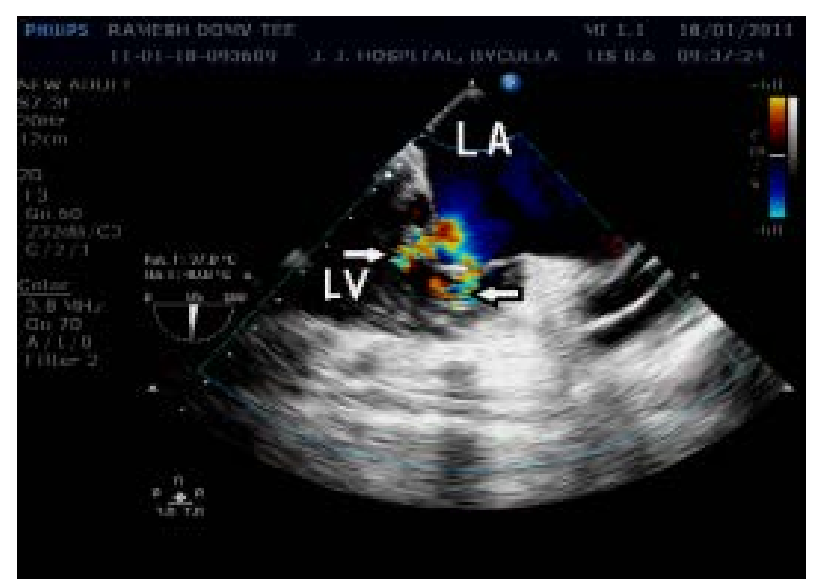

Figure 2. DOMV in TEE showing 2 jets across 2 orifices. 
Table 1. Patient characteristics: Case \#1-SK; case \#2-VD; case \#3-RP case \# 4-AS.

\begin{tabular}{|c|c|c|c|c|}
\hline & Case \#1 & Case \#2 & Case \#3 & Case \#4 \\
\hline Age & 27 & 17 & 28 & 22 \\
\hline Gender & Male & Male & Male & Female \\
\hline \multicolumn{5}{|l|}{$\begin{array}{c}\text { Clinical } \\
\text { presentation }\end{array}$} \\
\hline $\begin{array}{l}\text { Duration of } \\
\text { symptoms }\end{array}$ & 2 yrs & $1 \mathrm{yr}$ & $1 \mathrm{yr}$ & $2 \mathrm{yrs}$ \\
\hline Dyspnea & Class II & Class II & Class II & Class III \\
\hline $\begin{array}{l}\mathrm{h} / \mathrm{o} \text { rheumatic } \\
\text { fever in past }\end{array}$ & 12 yrs back & -- & 15 yrs back & 11 yrs back \\
\hline Rhythm & Regular & Regular & Regular & Regular \\
\hline Murmur & $\begin{array}{l}\text { MDM grade IV/IV at } \\
\text { apex, no systolic murmur }\end{array}$ & $\begin{array}{l}\text { MDM grade IV/IV at } \\
\text { apex, no systolic murmur }\end{array}$ & $\begin{array}{l}\text { MDM grade II/IV at apex, no } \\
\text { systolic murmur }\end{array}$ & $\begin{array}{l}\text { MDM grade IV/IV at apex, } \\
\text { no systolic murmur }\end{array}$ \\
\hline OS & -- & -- & + & + \\
\hline ECG & NSR, LAE & NSR, LAE & NSR, LAE & NSR, LAE \\
\hline \multicolumn{5}{|l|}{ ЕСНО } \\
\hline Dilated chambers & $\begin{array}{c}\text { LA, RA, RV; } \\
\text { LA size-63 × } 59 \text { mm }\end{array}$ & $\begin{array}{c}\text { LA, RA, RV; } \\
\text { LA size-62 ×53 mm }\end{array}$ & $\begin{array}{c}\text { Only LA ; } \\
\text { LA size- } 59 \times 49 \mathrm{~mm}\end{array}$ & $\begin{array}{c}\text { Only LA ; LA size- }-55 \times 44 \\
\text { mm }\end{array}$ \\
\hline Mitral valve & $\begin{array}{l}\text { Double orifice, both of near } \\
\text { equal size - spectacle } \\
\text { appearance }\end{array}$ & $\begin{array}{l}\text { Unequal orifice, } \\
\text { anterolateral larger }\end{array}$ & $\begin{array}{l}\text { Unequal orifice, } \\
\text { posteromedial smaller }\end{array}$ & $\begin{array}{c}\text { Unequal orifice } \\
\text { (posteromedial larger) }\end{array}$ \\
\hline $\begin{array}{l}\text { Mitral valve area } \\
\text { (MVA) } \mathrm{cm}^{2}\end{array}$ & Planimerty -0.67 each & $\begin{array}{l}\text { Posteromedial-0.64 } \\
\text { anterolateral-0.45, } \\
\text { total-1.09 }\end{array}$ & $\begin{array}{l}\text { Posteromedial-0.37 } \\
\text { anterolateral-0.57, } \\
\text { total—0.94 }\end{array}$ & $\begin{array}{l}\text { posteromedial }-0.8 \\
\text { anterolateral }-0.36\end{array}$ \\
\hline $\begin{array}{l}\text { Mean trans-mitral } \\
\text { gradient (mm Hg) }\end{array}$ & 16 & 12 & 11 & 11 \\
\hline MR & Trivial & No & $\begin{array}{c}\text { Grade I, from } \\
\text { posteromedial commissure }\end{array}$ & No \\
\hline $\begin{array}{l}\text { PASP (TR jet) } \\
\text { mmHg }\end{array}$ & 65 & 60 & 70 & 60 \\
\hline
\end{tabular}

--: absent; + : present; NSR—normal sinus rhythm; LAE—left atrial enlargement; PASP—pulmonary artery systolic pressure; MDM—mid diastolic murmur; LA — left atrium; RA —right atrium; RV—right ventricle. MR—-mitral regurgitation.

PLAX, PSAX, Apical 4 and 2 chamber and subxiphoid views were obtained to define mitral valve orifice, leaflets and sub valvular apparatus. Such patients were then enrolled into this study. Those patients with single orifice mitral valve, high score valves (Wilkins score > 8) [10], more than grade II mitral regurgitation (MR) \& severe multivalvular disease were excluded from the study, thus excluding patients with contraindication to BMV.

After written informed consent, the selected patients then underwent TEE guided balloon mitral valvuloplasty with 2 separate Inuoe balloons, one for each orifice, with size individualized according to patient's height (Table 2). All the required pressure measurements were done in the lab including the cardiac output measured using thermodilution. BMV was carried out under TEE guidance (for perfect septal puncture and crossing the separate orifices) using Inoue balloon of appropriate size (in accordance with patient's height) with intention to break central fibrous strand converting into a single orifice. We started with dilatation $4 \mathrm{~mm}$ less than the desired balloon size and then sequential dilatation were given with $1 \mathrm{~mm}$ gradation to achieve the desired MVA. Result of BMV was evaluated using measurement of MVA by planimetry, measuring the trans-mitral gradients and ruling out MR by color imaging (Figures 3-5). Patients are under follow up.

\section{Results}

Baseline characteristics: mean valve area by planimetry was $0.9 \mathrm{~cm}^{2}$; mean mitral valve score was 7.1 and mean 
Table 2. BMV using Inoue balloon.

\begin{tabular}{|c|c|c|c|c|c|c|c|c|}
\hline & \multicolumn{2}{|c|}{ Case \#1 } & \multicolumn{2}{|c|}{ Case \#2 } & \multicolumn{2}{|c|}{ Case \#3 } & \multicolumn{2}{|c|}{ Case \#4 } \\
\hline & Pre BMV & Post BMV & Pre BMV & Post BMV & Pre BMV & Post BMV & Pre BMV & Post BMV \\
\hline LVEDP mmHg & 15 & 10 & 13 & 12 & 12 & 12 & 16 & 13 \\
\hline LA mmHg & 49/28 (37) & 20/11 (15) & $37 / 16(23)$ & $21 / 9$ & $61 / 33(46$ & $24 / 14(18)$ & $55 / 38(42)$ & 21/9 (14) \\
\hline Trans mitral gradient (TMG) mm Hg & 22 & 5 & 10 & 1 & 24 & 6 & 26 & 1 \\
\hline Pulmonary arterymm Hg & $55 / 37(46)$ & $30 / 16(20)$ & $59 / 41(51)$ & $29 / 16(20)$ & $75 / 53(65$ & $35 / 19(24)$ & 98/35 (35) & $54 / 19(16)$ \\
\hline Cardiac output L/min & 5.3 & 6.2 & 4.8 & 5.4 & 4.4 & 4.9 & 4.5 & 5.2 \\
\hline MR & Trace & Mild & No & No & Grade I & Grade I & No & No \\
\hline $\begin{array}{l}\text { Balloon size } \\
\text { Used }\end{array}$ & 20,24 & & 20,24 & & 20,24 & & $\begin{array}{c}26 \\
\text { (smaller orifice not e }\end{array}$ & \\
\hline
\end{tabular}

LVEDP—left ventricular end diastolic pressure. LA—left atrial pressure.

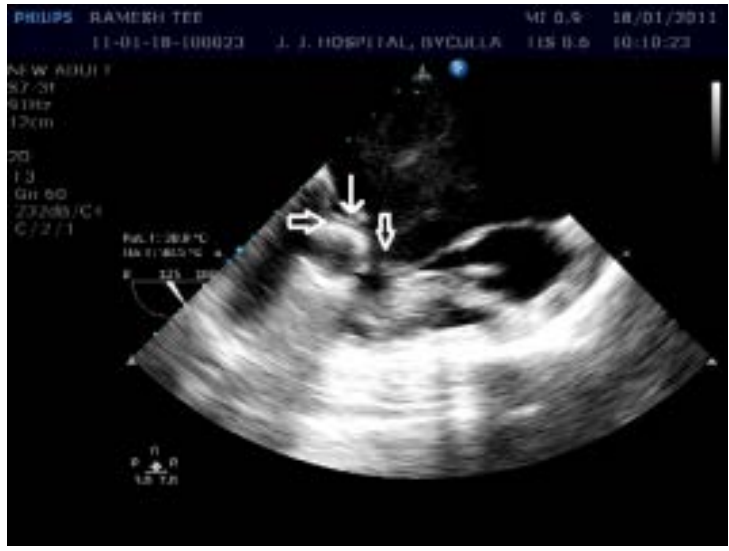

(a)

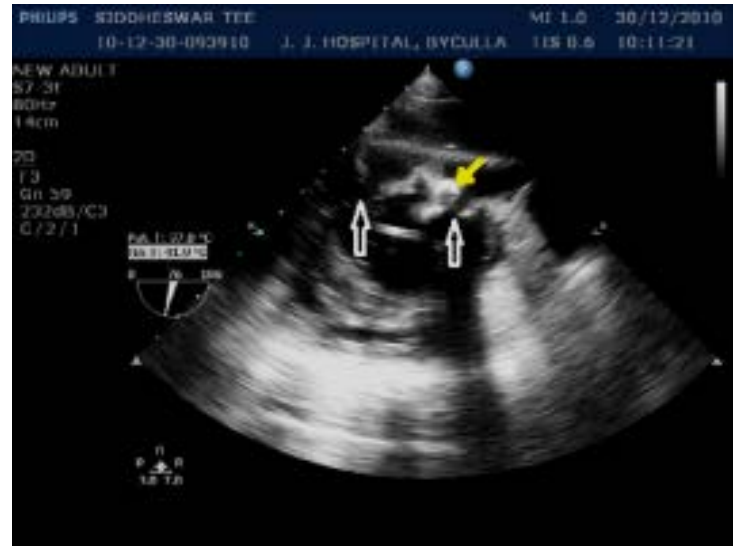

(b)

Figure 3. (a) (b) TEE images intra procedure: hollow arrows-orifices; solid arrows-balloon catheter.

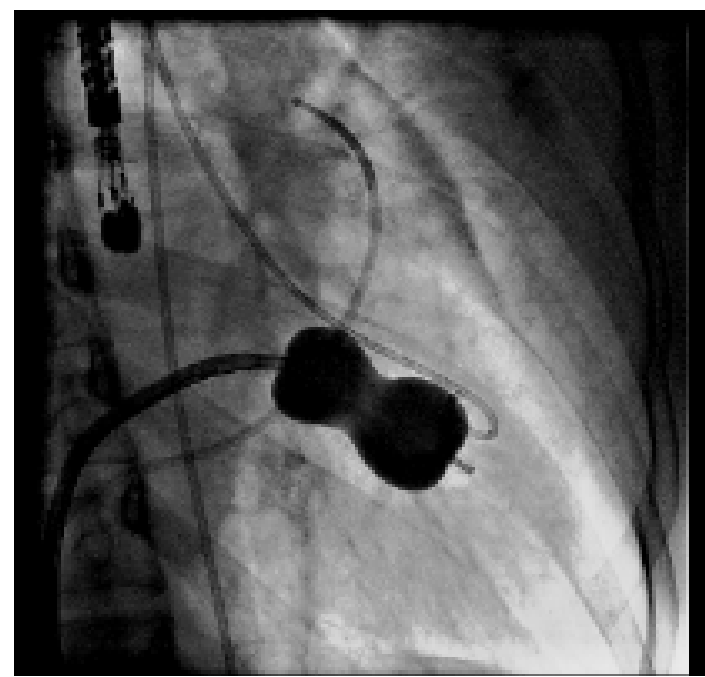

(a)

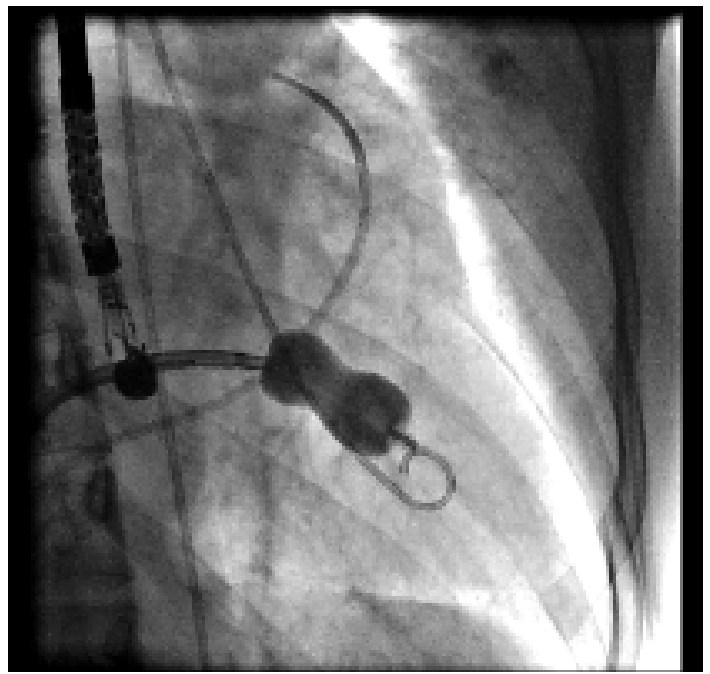

(b)

Figure 4. (a) (b) PTMC done with balloon in one orifice at a time. Pigtail is seen in the LV and a swan ganz catheter in pulmonary artery 


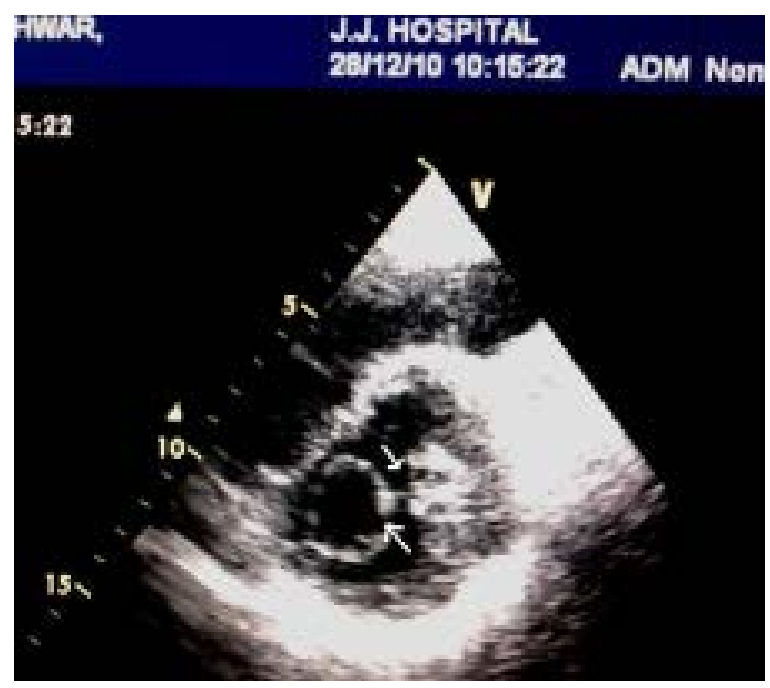

Figure 5. Post BMV TTE-shows increase in valve area.

diastolic gradient across mitral valve was $13 \mathrm{mmHg}$. One patient had larger posteromedial and one had larger anterolateral orifice. One patient had trivial and one had mild mitral regurgitation. Mean pulmonary artery systolic pressure was $57 \mathrm{mmHg}$ and mean cardiac output was $4.81 \mathrm{~L} / \mathrm{min}$. Post procedure: Successful BMV was carried out with mean post procedure valve area of $1.61 \mathrm{~cm}^{2}$, mean TMG of $4 \mathrm{mmHg}$, mean pulmonary artery pressure of $21 \mathrm{mmHg}$ and mean cardiac output was $5.3 \mathrm{~L} / \mathrm{min}$. In case 4, the smaller anterolateral orifice could not be crossed. Other 3 cases each orifice was crossed with different balloon catheters depending on height of the patient. Only in one patient (case 2) the double orifice could be converted to single while in remaining three it could not; however the fall in TMG was significant hence no further attempts were made. There was no significant increase in post procedure MR (Figures 3-5).

\section{Limitations}

1) Though BMV in all the patients significantly reduced the TMG and symptomatic improvement, bridging fibrous strand could not be broken in 3 cases hence the effect of resection of fibrous strand on further relief of stenosis or development of fresh MR could not be studied.

2) Morphology of the valves was judged by two-dimensional echocardiography and could not be confirmed either with 3D images or surgically since no patient was sent for surgery.

\section{Conclusion}

Acquired double orifice mitral valve stenosis of favourable morphology can be effectively treated with BMV using Inoue balloon under TEE guidance to reduce the procedure time, to dilate the desired orifice and to reduce the complication. Desired fall in the TMG should be the goal of the procedure rather than to achieve a single orifice valve. Whether same technique can be used to treat the DOMV of congenital origin needs further studies.

\section{Discussion}

Double orifice mitral valve was found in $1 \%$ of autopsied cases of congenital heart disease (CHD) in the Cardiac Registry of the Children's Hospital, Boston [11]. Approximately 50\% of all cases of double orifice mitral valve are detected during investigation of other CHDs [11]. DOMV is a rare malformation characterized by 2 valve orifices with separate subvalvular tissue for each orifice. The presence of tendinous attachments to both openings distinguishes congenital DOMV from acquired lesions such as perforation or partial fusion of leaflets caused by inflammatory lesions (rheumatic) or traumatic ruptures. Most common associated lesion is AVCD ${ }^{5}$. In presence of intact AV septum, left sided obstructive lesion (commonly coarctation of aorta) is the most common associated finding [1] [12]. 
Subvalvular structures, especially the tensor apparatus, invariably show various degree of abnormality [3]-[8] [11]. Although double orifice mitral valve may allow normal blood flow between the left atrium and ventricle, it can substantially obstruct mitral valve inflow or produce mitral valve incompetence.

Recognition of double orifice mitral valve and awareness of the anatomic variations are important to achieve good therapeutic results. Treatment is only necessary if significant MS or MR is present.

Trowitzsch et al. [1] described 3 subtypes of DOMV based on echocardiographic studies by sweeping the transducer from apex to base:

1) Complete bridge type: Two separate orifices exist from the leaflet tip all the way through body of leaflet till annulus. Both orifices can be equal in size giving an appearance of a pair of spectacles or they can be of unequal size. Papillary muscles are usually normal and chordae surrounding each orifice are attached to one papillary muscle. In this type dilatation of posteromedial orifice is feasible by means of BMV.

2) Incomplete bridge type: A connection is seen between anterior and posterior leaflet only at edge. Mid basal level of mitral valve appears single orifice.

3) Hole type: A single orifice is present at leaflet level. Additional smaller orifice is present at one of the two commissures oriented roughly at the right angle to main orifice. This second orifice is seen about mid leaflet level.

Accessory (smaller) orifice has been described anterolateral in $41 \%$, posteromedial in $44 \%$ and of equal size in $15 \%$ of patients [11]. When accessory orifice was posteromedial, common AVCD was almost always present (in 92\%) [1] [11]. When AV septum is intact, mitral valve is either normal (50\%) or stenotic (42\%) but rarely can be regurgitant while in presence of common AVCD mitral valve can be normal or regurgitant (40\%) and rarely stenotic [11].

Usually congenital however mitral valve can be double orifice due to acquired conditions like rheumatic heart disease, trauma during BMV or infective endocarditis. ${ }^{3}$ Presence of tendinous attachment to both the openings distinguishes DOMV from acquired lesions. Selected cases of double orifice mitral valve with MS are amenable to percutaneous transcatheter balloon dilatation. This option offers a nonsurgical method of relieving obstruction [13]. Successful dilatation has been reported in patients with the bridge type of double orifice mitral valve, especially if the bridge is incomplete [14]. Stepwise dilatations by using an Inoue balloon are applied to the posteromedial orifice of the double orifice mitral valve. The results are best if the double orifice mitral valve is an isolated defect and if no major deformity of the subvalvular tensor apparatus is present.

In case of congenital stenotic DOMV, central bridge in complete variety can cause severe stenosis as bridge is made up of valve tissue or chordae. While resection in incomplete variety may relieve obstruction, this forms the basis of current case report managing acquired MS with double orifice by division of fibrous bridge using Inuoe balloon. Use of Inoue balloon for breaking the fibrous band by dilatation of only the posteromedial orifice has been described earlier [13]. But in that study it was not possible to enter the other orifice in a few cases.

In this study, the clinical presentations and physical findings in patients were indistinguishable from those in rheumatic MS including history of rheumatic fever (except case 2). However, vigilance acquired from thorough echocardiography including TEE contributed to expeditious echocardiographic identification of the incomplete bridge DOMV in these patients. We have demonstrated that Inoue BMV can be safely and successfully applied to each orifice and get good hemodynamic results even if the band is not broken completely. We had good hemodynamic results and good prognosis at 48 month follow up even though the band could be broken in only one patient case 2 .

Based on our experience in this study, several important technical tips and guidelines have evolved. First, transseptal catheterization performed under TEE guidance helps to cross the septum at the thinnest portion so as not to face any resistance in balloon movement. Second, balloon crossing of the posteromedial orifice is simple but transeosophagel echocardiography guidance should be used to cross the balloon into either orifice and stepwise dilations of the orifices are sufficient to decrease the gradient across the valve and it is not always necessary to break the fibrous band. Third, balloon catheter selection can be based on the height-derived reference size as in ordinary cases of MS. And last, stepwise dilations can be initiated at a balloon diameter of $4 \mathrm{~mm}$ less than the reference size. We could successfully increase the orifice size and decrease the TMG with serial dilatations of both the orifices. All the patients are doing well at 36 - 48 month follow up

In summary, in symptomatic patients with stenotic DOMV of acquired origin (RHD), Inoue BMV with stepwise dilations applied to both orifices appears to be a safe and effective therapeutic modality. The long term outcome of BMV in cases with DOMV of rheumatic origin needs further studies. 


\section{References}

[1] Trowitzsch, E., Bano-Rodrigo, A., Burger, B.M., Colan, S.D. and Sanders, S.P. (1985) Two-Dimensional Echocardiographic Findings in Double-Orifice Mitral Valve. Journal of the American College of Cardiology, 6, 383-387. http://dx.doi.org/10.1016/S0735-1097(85)80176-5

[2] Greenfield, W.S. (1876) Double Mitral Valve. Trans Pathol Soc London, 27, 128-129.

[3] Hoffman, P., Stumper, O., Groundstroem, K. and Sutherland, G. (1993) The Transesophagealechocardiographic Features of Double-Orifice Left Atrioventricular Valve. Journal of the American Society of Echocardiography, 6, 94-100. http://dx.doi.org/10.1016/S0894-7317(14)80263-0

[4] Wenink, A.C.G. and Gittenberger-de Groot, A.C. (1982) Left and Right Ventricular Trabecular Patterns. Consequence of Ventricular Septation and Valve Development. British Heart Journal, 48, 462-468. http://dx.doi.org/10.1136/hrt.48.5.462

[5] Linka, A.Z., Fatio, R. and Jost, C.A. (2000) Images in Cardiology: Double Orifice Mitral Valve. Heart, 84, 244. http://dx.doi.org/10.1136/heart.84.3.244

[6] O’Shea, J.P., Abascal, V.M., Wilkings, G.T., Marshall, J.E., Brandi, S., Acquatella, H., et al. (1992) Unusual Sequelae after Percutaneous Mitral Valvuloplasty: A Doppler Echocardiographic Study. Journal of the American College of Cardiology, 19, 186-191. http://dx.doi.org/10.1016/0735-1097(92)90071-T

[7] Wakai, C.S. and Edwards, J.E. (1958) Pathologic Study of Persistent Common Atrioventricular Canal. American Heart Journal, 56, 779-794. http://dx.doi.org/10.1016/0002-8703(58)90221-7

[8] Sherman, F.E. (1963) An Atlas of Congenital Heart Disease. Lea \& Febiger, Philadelphia, 123, 146, 152-154.

[9] Sharma, S., Loya, Y.S. and Daxini, B.V. (1991) Coarctation of Aorta with Unusual Association of Diverticulum of the Left Ventricle and Double-Orifice Mitral Valve. International Journal of Cardiology, 30, 113-115. http://dx.doi.org/10.1016/0167-5273(91)90132-9

[10] Wilkins, G.T., Weyman, A.E., Abascal, V.M., Block, P.C. and Palacios, I.F. (1988) Percutaneous Balloon Dilatation of the Mitral Valve: An Analysis of Echocardiographic Variables Related to Outcome and the Mechanism of Dilatation. British Heart Journal, 60, 299-308. http://dx.doi.org/10.1136/hrt.60.4.299

[11] Bano-Rodrigo, A., Van Praagh, S., Trowitzsch, E. and Van Praagh, R. (1988) Double-Orifice Mitral Valve: A Study of 27 Postmortem Cases with Developmental, Diagnostic and Surgical Considerations. American Journal of Cardiology, 61, 152-160. http://dx.doi.org/10.1016/0002-9149(88)91322-7

[12] Das, B.B., Pauliks, L.B., Knudson Jr., O.A., Kirby, S., Chan, K.-C., Valdes-Cruz, L., Cavre, R.O., et al. (2005) Double-Orifice Mitral Valve with Intact Atrioventricular Septum: An Echocardiographic Study with Anatomic and Functional Considerations. Journal of the American Society of Echocardiography, 18, 231-236. http://dx.doi.org/10.1016/j.echo.2004.12.001

[13] Lo, P.-H., Hung, J.-S., et al. (2003) Inoue Balloon Mitral Valvuloplasty in Double-Orifice Mitral Stenosis. Journal of Invasive Cardiology, 15.

[14] Mercer, J.L. and Tubbs, O.S. (1974) Successful Surgical Management of Double Mitral Valve with Subaortic Stenosis. The Journal of Thoracic and Cardiovascular Surgery, 67, 440-442. 